\title{
The knowledge about patient safety among undergraduate nurse students in Cyprus and Greece: a comparative study
}

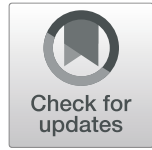

\author{
Maria Dimitriadou ${ }^{1 *}$, Anastasios Merkouris ${ }^{1}$, Andreas Charalambous ${ }^{1}$, Chrysoula Lemonidou $^{2}$ and \\ Evridiki Papastavrou ${ }^{1}$
}

\begin{abstract}
Background: The Patient safety movement contributed to the reduction of preventable adverse events associated with health care. Although patient safety issues have received the attention of educators in the health care studies, there is evidence that in nursing education and the associated curricula it is not well-incorporated. This may not allow students to acquire scientific knowledge and develop strong competencies to assure patient safety throughout their professional life. The aım of the study was the exploration of the undergraduate nursing student perspectives regarding knowledge received during their training about patient safety-related issues.

Methods: A descriptive comparative study was conducted with three and four-year undergraduate nursing students from the Cyprus Republic $(n=243)$ and Greece $(n=367)$. All students were surveyed using the Health Professional Education Patient Safety Survey (H-PEPSS) to describe students' knowledge in the classroom and clinical setting.

Results: Students' Knowledge about patient safety was expressed significantly higher $(p<0.001)$ in the classroom (mean $=4.0)$ than the clinical setting (3.7) (1-5 scale). The knowledge in the dimension "clinical aspects" received the highest score and "working in teams" received the lowest. Also, differences were recorded between countries with Cypriot students reporting higher level of knowledge than the Greek students in most of the dimensions.

Conclusion: The findings revealed the gap between theory and practice and the need for collaboration between the two settings. Also, students reported relatively higher knowledge with regards to the technical aspects of patient safety. Still, they were less knowledgable about the sociocultural aspects of the patient, such as working in teams.
\end{abstract}

Keywords: Nursing students, patient safety, undergraduate education, curriculum

\footnotetext{
* Correspondence: maria.dimitriadou@cut.ac.cy

'Department of Nursing, School of Health Sciences, Cyprus University of Technology, 15 Vragadinou Str, 3041 Limassol, Cyprus

Full list of author information is available at the end of the article
}

(c) The Author(s). 2021 Open Access This article is licensed under a Creative Commons Attribution 4.0 International License, which permits use, sharing, adaptation, distribution and reproduction in any medium or format, as long as you give appropriate credit to the original author(s) and the source, provide a link to the Creative Commons licence, and indicate if changes were made. The images or other third party material in this article are included in the article's Creative Commons licence, unless indicated otherwise in a credit line to the material. If material is not included in the article's Creative Commons licence and your intended use is not permitted by statutory regulation or exceeds the permitted use, you will need to obtain permission directly from the copyright holder. To view a copy of this licence, visit http://creativecommons.org/licenses/by/4.0/. The Creative Commons Public Domain Dedication waiver (http://creativecommons.org/publicdomain/zero/1.0/) applies to the data made available in this article, unless otherwise stated in a credit line to the data. 


\section{Background}

The fundamentals of good nursing are reflected in Florence Nightingale's (1896) quoted words "First, do no harm" and are expressed in codes of ethics and responsibility $[1,2]$. Today healthcare organisations face many challenges in keeping and promoting safe care for patients due to resources shortage, the increasing demand for care, technological advancements and shifting population demographics. Despite these challenges, patient safety should be considered a human-right issue and health care systems should be committed to all their patients [1].

Globally, it has been estimated that one out of ten patients experienced safety issue(s) while receiving hospital care; this represents the 14th cause of the global disease burden [3]. A survey among European citizens showed that half of the respondents felt that they might be harmed while receiving healthcare and a high percentage of the respondents claimed that they or a family member had experienced an adverse event during healthcare [4]. The economic burden of unsafe care is estimated as the annual cost of common adverse events (i.e. pressure ulcers, hospital-associated infections, thromboembolism, medication error) being equivalent to hiring 2,000 General Practitioners or 3,500 hospital nurses [5]. It is alarming to realise that many adverse events are preventable, and up to 28 USD billion has been saved in 5 years by improving safety in hospitals [5]. These facts corrode public trust and build vast health, financial and ethical burden on the healthcare systems and the broader society.

'Patient safety' is defined as the prevention of unnecessary harm to a patient during the process of health care and the reduction of the risk of unnecessary injury, associated with health care, to an acceptable minimum [6]. Patient safety is the outcome of both system effectiveness and individual performance design to minimise the risk of injuries to patients from the care that is intended to help them [7]. That encompasses shifting from the position of thinking patient safety as a technical issue to the position of system-related factors and the involvement of many individuals [8]. These factors are referred to as non-technical or sociocultural skills of patient safety $[9,10]$. Non-technical skills are defined as 'a set of social and cognitive (analytical and personal behaviour) skills that support high-quality, safe, effective, and efficient interprofessional care within the complex healthcare system' ( $p$. 6) [11]. Key elements, included in sociocultural skills, are effective communication, teamwork, skills of recognising and managing risky situations, optimising human and environmental factors and contributing to a culture aware of the importance of reporting and learning from incidents [10].
It is important to note that nurses are the largest group of health providers as they make up more than $50 \%$ of the practicing health workforce and they have a central role in protecting patient safety, as they are the providers with the most prolonged and most direct patient contact [12]. Thus, nurses, more than any other health professionals, are likely to recognise, prevent, and correct malpractice in workflow and communication [12].

Undergraduate nursing education is an important starting point in advancing patient safety in the domains of knowledge, attitude, and skills in preparing future nurses [10, 12-14]. Students are considered an integral and indispensable component of the health care system, contributing to safety care, highlighted in the statements "fresh pair of eyes, keen to learn.and the safety leaders of the future"[2]. As such, exposure to the concept of patient safety early in undergraduate education is encouraged by two facts: firstly, more preventable errors are made by nurses shortly after graduation than later in their career [15], and secondly, the new graduates bring current evidence-based theory and a fresh vigour to the workplace[16]. To a degree, nursing education is associated with patient mortality [17-19] and the level of nurse-reported adverse events [20, 21]. Today a gap of evidence about the extent and type of the role of nursing education in patient safety improvement [12, 22], as well as the perceived confidence of undergraduate nursing students in specific patient safety areas still exist [23].

The landmark in advancing patient safety as a priority and quality indicator was the United State's report "Error is human",[24] and the report "An Organization With a Memory" launched later by the United Kingdom [25]. Since then, healthcare professional education has been seen as one of the most crucial improvement intervention for reducing the risk of harm in order students, as the future workforce, to understand the nature of risk in health care and the need of bolstering systems [10, 24, $26,27]$. Traditionally, health care professional curricula focus on clinical skills, such as diagnosis, treatment, medication administration and keeping aseptic techniques $[12,28]$. However, unintended patient harm is predominantly a consequence of system failure [8]. For that, educational and organizational challenges extended the Individual responsibility further to include effective teamwork, information sharing, a collaboration between professions and respect for each other's roles and perspectives [22] in order patient safety learning to be delivered in an integrated way.

Patient safety awareness has emerged in undergraduate education, aiming to change organisational culture and recommend teaching and learning skills related to patient safety. At an international level, the World Health Organization (2011) has developed "The MultiProfessional Patient Safety Curriculum Guide". In 
Europe, the European Network for Patient Safety [26] project encapsulated the Council of European Union recommendations given in 2009/C 151/01 and raised awareness of integrating patient safety in the health professionals' curricula. This approach went beyond formal learning in the classroom, addressing guidelines in improving understanding in clinical settings. Finally, at a national level, regulatory bodies have provided a framework for learning interventions [10, 29-31]. All of them focus on the development of professional competencies and place patient safety beyond the actual technical provision of care (i.e. administration of medicine) to the improvement of the system that underpins practice. They identified human factors and the way these factors relate and interact within the system as a significant element of patient safety domain. The problem is that the framework contexts about patient safety principles are not domain-specific [32]. So, some additional knowledge relevant to the nursing specialisation (i.e.empowerment, psychological support and interprofessional relationships) is recommended [33].

Today, two decades later, patient safety education for health professionals is the least implemented among all the initiatives [14, 34]. Literature has identified that teaching patient safety to undergraduate nursing students is a necessity, however, there is still no consistency in the teaching methods nor an agreement on which areas to focus or prioritise. Patient safety remains a "hidden element" within the curriculum over the years [14, 35-41]. It is incorporated into an already overwhelming nursing curriculum slowly and somewhat sporadically $[12,39,40,42]$. This, therefore, leaves students little opportunity to clarify and understand non-technical human factors role over technical competencies in keeping patient safe[43].

Earlier evidence indicated that students felt more confident in technical aspects than the sociocultural aspects of patient safety [9, 44-47]. For example, students reported less knowledge regarding teamwork issues, especially during their clinical placements [35, 46], although they valued teamwork including patient participation in health care planning [48]. However, this evidence derived mainly from Canada, USA and Australia and partly from Europe (e.g. the UK, Finland and Italy) [32, 49-53]. Furthermore, students' knowledge about patient safety beyond the formal classroom in the actual workplace was limited $[54,55]$.

Students felt that more class time was spent on teaching pathophysiology and treatment over nursing interventions [12]. As a result, not enough time was left to discuss nursing care and patient safety issues. Consequently, students considered themselves unsafe and not knowledgeable enough regarding patient matters in real practice [39, 40,51]. Other evidence showed lack of faculty familiarity in teaching such courses [40] and the lack of educators' confidence or interest to integrate patient safety in the curriculum $[12,29,56]$. A qualitative study has found that the WHO 11 topics were either not addressed at all (i.e. human factors) or were taught in a manner that failed to link patient safety [33].

Similarly, a European study, under the COST Action project RANCARE (https://www.cost.eu/actions/CA152 08), across 27 countries, has found that safety issues were not included as a separate module. Even if they were indeed included in some syllabi, they were not taught as a stand-alone topic but were rather dispersed across the curriculum in several other subjects giving the impression of limited importance. Also, the above study identified differences in nursing education across and within the countries examined [14].

Reconstructing nursing education is challenging. The growing literature indicates a gap in knowledge, about where and how patient safety is effectively taught in the pre-registration nursing program and about the level of knowledge students should obtain in specific patient safety areas $[14,55,57]$. Evaluation of nursing students perceptions on what they have learned about patient safety in both the classroom and the clinical practice could be a starting point, especially in the case where these students come from different nationalities and cultures and their viewpoints are brought to a bear $[26,34]$. Studying multiple students perceptions is the best way for educators to understand the weaknesses and omission of the education system. Under the sight of the limIted evidence in the perceived competence in patient safety in Europe, the data of the current study will add value to national efforts as well as the European collaboration to the process of designing, developing, delivering and evaluating a learning intervention either in class or the workplace. To our knowledge, this is the second comparative study between countries focusing on undergraduate nursing students' perceptions of patient safety issues [50, 51].

In short, a nursing education description in Cyprus and Greece follows. Training of nurses in Cyprus and Greece conforms to the EU standards for mutual recognition of qualifications [58]. The duration of undergraduate nursing studies is four years covering 240 ECTS (European Credit Transfer and Accumulation System). Cyprus has only the option of a university degree graduation. Regarding the clinical practice, two supervision models have been adopted, that of the Nurse educator and the mentor. The mentor and the students are both supernumeraries in a ration 1:5 [59]. In Greece, at the time of data collection, there were two levels of higher nursing education (university and technological degree) and vocational education for nursing assistants (two-year studies). During clinical practice, students are 
trained either by nursing staff (mainly graduated from the university) or by graduate or doctoral students with clinical experience, whereas at times nursing professors visit students for ensuring that learning outcomes are fulfilled.

\section{Method}

Aim

The aim of the study was the exploration of the nursing student perspectives about patient safety knowledge and the nursing curricula among the populations of Greece and Cyprus.

\section{Study desıgn, setting and participants}

A descriptive - comparative study. The target population of the study included all three and four-year students enrolled in an undergraduate nursing program as regulated by the European directive 2013/55/EU [58] in both countries. Particularly, in Cyprus, 229 students, from the 4 universities (1 public and 3 private) offering nursing bachelor program and in Greece, 381 students, from the biggest university of Greece offering nursing bachelor program were enrolled. The selection of Cyprus and Greece was based on the continuous collaboration of the two countries in educational matters, shared historical roots, tradition and culture, as well as the fact that they are both Greek-speaking countries. The selection of all three and four-year students was because they had completed several clinical placements and spent longer periods in the clinical practice than students of the other years. Also, senior students had focused more on non-technical skills, like leadership and guidance than the junior ones who had been directed toward essential clinical nursing skills [60]. The questionnaires were administered to all the students during their last classroom lesson between May and June 2018. No curriculum changes occurred over the study period.

\section{Study instrument}

The study used the Health Professional Education in Patient Safety Survey (H-PEPSS) developed by Liane R. Ginsburg [9]. The instrument was developed to reflect specific patient safety educational outcomes regarding 'non-technical skills', as well as the gap between classroom knowledge and clinical competence[52, 61]. The questionnaire includes 38 items divided into 3 sections (Secs. 3, which explores the comfort of speaking up (6 items) hasn't been included in the present study): The 1st section is composed of 27 items, divided into 7 dimensions: one dimension focuses on clinical safety issues (technical aspect) (4 items) and six dimensions focus on the sociocultural aspects of patient safety, proposed by the Canadian Patient Safety Institute (CPSI) [10]. These are: (a) Contributing to a culture of patient safety (4 items); (b) Working in teams for patient safety (6 items); (c) Communicating effectively for patient safety (3 items); (d) Managing safety risks (3 items); (e) Optimising human and environmental factors (3 items); and (f) Recognising, responding to and disclosing adverse events and close calls (4 items). Students were asked to indicate their agreement for each item regarding contents learned in the classroom and during their clinical experience with a separate score on a 5-point Likert scale ranging from $1=$ 'strongly disagree' to $5=$ 'strongly agree'. The 2nd section is composed of five items focusing on how broader PS issues are addressed in health professional education. In both sections, each item is reported as a statement, scored on a 5-point Likert scale ranging from $1=$ 'strongly disagree' to $5=$ 'strongly agree'. Higher scores represent higher levels of self-perceived students' knowledge about patient safety, in the specific areas. The psychometric properties of the instrument H-PEPSS were examined by several researchers $[9,44,45,52,62]$ who concluded that it is a reliable (Cronbach's a showed $>0.72$ ) and a valid instrument, capable of evaluating competencies in patient safety perceived by undergraduate nursing studies. Demographic characteristics, including age, gender, year of study and country were also collected.

\section{Instrument translation}

In order to verify the cross-cultural adaptation of the $\mathrm{H}$ PEPSS a forward- backward translation, cultural and linguistic adaptation and a pilot study were attended, following the guide of the World Health Organization process of translation and adaptation of instruments [63]. Firstly, a native English-speaking academic nursing staff and a certified translator translated independently the H-PEPSS from English into Greek. Then the two translators along with the two authors (MD, EP) proofread the translated instrument and agreed on the 1st draft. Then, two native English nurses, a doctoral degree holder and a doctoral degree candidate, back-translated the 1st Greek H-PEPSS draft. Subsequently, a new committee, consisting of two translators and three experts in nursing education from Greece and Cyprus, compared the back-translation to the original, with emphasis on the conceptual and cultural, rather than the linguistic, equivalence. Then, a pilot study was conducted involving a convenience sample of 60 newly graduate nursing students. The students evaluated the fluency, the readability and the comprehensibility of the items. Finally, the appropriate adaptations were made according to the received feedback.

\section{Ethical considerations}

Approval was asked by the Cyprus National Bioethics Committees (CNBC EP: 2018.01.61) and the Ethics 
Committees of each university. Also, permission to use the H-PEPSS questionnaire was given by the author [9] via emall. The participants were informed in writing about the purpose of the study. Completing and returning the questionnaire was considered as consent to participate in the study. Finally, confidentıality as well as anonymity were assured, and the data was stored in a manner compliant with data protection regulations [64].

\section{Data analysis}

SPSS 21.0 software (SPSS Inc., Chicago, IL) was used to perform descriptive and inferential statistical analyses. No imputation was done for missing data as was $<1 \%$ observed at random. Statistically significant results were considered with p-value $<0.05$. Demographic, class, and clinical setting-related data were summarised using descriptive statistics, mean ( \pm standard deviation) calculated in the range of 1 to 5 . Patient safety scores for each domain were calculated by averaging the items. Paired $t$ tests were performed to identify significant differences in patient safety competencies between the classroom and clinical scores, and independent samples t-tests between countries and year of studies.

\section{Results}

\section{Demographic characteristics}

Four-hundred and eighty-six students responded in the study (197 from Cyprus, and 289 from Greece) out of 610 , giving a response rate of $79.5 \%$ of the total participants. The majority were female (78.2\% Cyprus, $87.2 \%$ Greece. Among the participants from Greece, 130 (45\%) and 159 (55\%) were 3rd and 4th -year students, respectively. Cypriot students attended a range of institutions and $104(52.8 \%)$, and 93 (47.2\%) were three and fouryear students, respectively.
The perceived knowledge in patient safety domains in the classroom and the clinical setting

As shown in Table 1, the internal consistency of the overall scale (Cronbach's alpha) demonstrated an excellent internal consistency index $\mathrm{a}=0.95$ and $\mathrm{a}=0.96$ for the classroom and clinical setting, respectively. For the classroom dimensions, Cronbach's alpha ranged from 0.89 (communicating effectively) to 0.85 (Understanding human and environmental factors) while for the clinical dimensions it ranged from 0.92 (working in teams) to 0.87 (Recognise and respond to an adverse event). The overall mean score was $4.0 \pm$ 0.6 in the classroom setting, and $3.7 \pm 0.8$ in the clinical setting, from a range of 1 to 5 . Nursing students exhibited the highest mean score in what they learned about, in the clinical safety dimension in both the classroom (4.4 \pm 0.7$)$ and the clinical setting $(3.9 \pm$ $0.9)$. The least knowledge was reported in "working in teams with other professionals" in both settings.

\section{Differences in students' perceptions between the year of study and countries.}

Regarding the year of studies, 4-year students (irrespective of country of origin) exhibited higher scores in all HPEP SS dimensions when compared to 3-year students. Similarly to the comparison of means between countries, the highest score was reported in "clinical safety" and the lowest in "working in teams". Also, in most of the dimensions, significant differences $(p<0.05)$ between the three and four-year students were identified. Three dimensions in the classroom setting and five dimensions in the clinical setting were found statistically significant $(p<0.05)$ with 4 -year students having a higher level of agreement when compared to three-year students (Table 2).

When comparing the Cypriot to the Greek students, as shown in Table 2, significant differences $<0,001$

Table 1 Students' perspectives of knowledge in patient safety dimensions ( $1^{\text {st }}$ section of the questionnaire- HPEPSS) in the classroom and clinical practice in both countries (Cyprus and Greece $(n=486)$ range $=1-5$ )

\begin{tabular}{|c|c|c|c|c|}
\hline \multirow{2}{*}{$\begin{array}{l}\text { Patient safety dimensions } \\
\text { Cyprus and Greece }(n=486)\end{array}$} & \multirow{2}{*}{$\begin{array}{l}\text { Classroom } \\
\text { Mean (SD) }\end{array}$} & \multirow{2}{*}{$\begin{array}{l}\text { Clinical } \\
\text { Mean (SD) }\end{array}$} & \multicolumn{2}{|c|}{ Paired samples t-test } \\
\hline & & & $\mathrm{t}$ & $p$-value* \\
\hline Overall Scale & $4.0(0,6)$ & $3.7(0,8)$ & 10.507 & $<0.001$ \\
\hline Clinical Safety & $4.4(0,6)$ & $3.9(0,9)$ & 11.693 & $<0.001$ \\
\hline Working in teams & $3.7(0,8)$ & $3.5(0,9)$ & 6.808 & $<0.001$ \\
\hline Communicating effectively & $4.1(0,8)$ & $3.8(0,9)$ & 9.039 & $<0.001$ \\
\hline Manage Risk & $3.9(0,9)$ & $3.7(1,0)$ & 6.108 & $<0.001$ \\
\hline Human and environmental factors & $3.9(0,9)$ & $3.7(1,0)$ & 5.428 & $<0.001$ \\
\hline Adverse events & $3.9(0,8)$ & $3.6(0,9)$ & 7.212 & $<0.001$ \\
\hline Culture of safety & $4.1(0,8)$ & $3.8(0,9)$ & 7.601 & $<0.001$ \\
\hline
\end{tabular}

*Sig. (2-tailed) 
Table 2 Differences in Students' perspectives of knowledge in patient safety dimensions between year of studies and countries (range $=1-5$ )

\begin{tabular}{|c|c|c|c|c|c|c|c|c|}
\hline \multirow[t]{2}{*}{ Patient safety dimensions } & \multirow{2}{*}{$\begin{array}{l}\text { Cyprus } \\
(n=197) \\
\text { Mean (SD) }\end{array}$} & \multirow{2}{*}{$\begin{array}{l}\text { Greece } \\
(n=289) \\
\text { Mean (SD) }\end{array}$} & \multicolumn{2}{|c|}{$\begin{array}{l}\text { Independent } \\
\text { samples t-tests }\end{array}$} & \multirow{2}{*}{$\begin{array}{l}\text { 3rd year }(n=234) \\
\text { Mean (SD) }\end{array}$} & \multirow{2}{*}{$\begin{array}{l}\text { 4th year }(n=252) \\
\text { Mean (SD) }\end{array}$} & \multicolumn{2}{|c|}{$\begin{array}{l}\text { Independent } \\
\text { samples t-tests }\end{array}$} \\
\hline & & & $\mathrm{t}$ & $p$-value* & & & $\mathrm{t}$ & $p$-value* \\
\hline \multicolumn{9}{|l|}{ Classroom setting } \\
\hline Clinical Safety & $4.7(0.5)$ & $4.2(0.7)$ & 9.745 & $<0.001$ & $4.3(0.7)$ & $4.5(0.6)$ & -3.216 & 0.001 \\
\hline Working in teams & $4.1(0.7)$ & $3.5(0.8)$ & 9.343 & $<0.001$ & $3.7(0.8)$ & $3.8(0.8)$ & -1.405 & 0.160 \\
\hline Communicating effectively & $4.5(0.6)$ & $3.8(0.8)$ & 10.175 & $<0.001$ & $4.1(0.8)$ & $4.1(0.8)$ & 0.371 & 0.711 \\
\hline Manage Risk & $4.3(0.7)$ & $3.6(0.8)$ & 9.957 & $<0.001$ & $3.8(0.8)$ & $4.0(0.8)$ & -2.291 & 0.022 \\
\hline Human and environmental factors & $4.3(0.8)$ & $3.7(0.8)$ & 8.202 & $<0.001$ & $3.9(0.8)$ & $3.9(0.9)$ & -0.285 & 0.776 \\
\hline Adverse events & $4.2(0.7)$ & $3.6(0.8)$ & 8.856 & $<0.001$ & $3.8(0.8)$ & $3.9(0.9)$ & -1.361 & 0.143 \\
\hline Culture of safety & $4.3(0.6)$ & $3.8(0.7)$ & 6.649 & $<0.001$ & $4.0(0.8)$ & $4.1(0.7)$ & -2.654 & 0.008 \\
\hline \multicolumn{9}{|l|}{ Clinical setting } \\
\hline Clinical Safety & $4.5(0.6)$ & $3.5(0.8)$ & 13.107 & $<0.001$ & $3.8(0.9)$ & $4.0(0.9)$ & -1.968 & 0.045 \\
\hline Working in teams & $4.0(0.8)$ & $3.2(0.8)$ & 11.487 & $<0.001$ & $3.4(0.9)$ & $3.6(0.9)$ & -1.790 & 0.075 \\
\hline Communicating effectively & $4.3(0.8)$ & $3.4(0.8)$ & 11.232 & $<0.001$ & $3.7(0.9)$ & $3.8(0.9)$ & -2.009 & 0.045 \\
\hline Manage Risk & $4.1(0.8)$ & $3.3(0.9)$ & 9.914 & $<0.001$ & $3.5(0.9)$ & $3.8(0.9)$ & -3.287 & 0.001 \\
\hline Human and environmental factors & $4.0(0.9)$ & $3.4(0.9)$ & 6.411 & $<0.001$ & $3.6(0.9)$ & $3.8(0.9)$ & -2.287 & 0.023 \\
\hline Adverse events & $4.0(0.7)$ & $3.3(0.8)$ & 8.807 & $<0.001$ & $3.5(0.8)$ & $3.8(0.9)$ & -3.442 & 0.001 \\
\hline Culture of safety & $4.1(0.8)$ & $3.6(0.9)$ & 7.039 & $<0.001$ & $3.7(0.9)$ & $3.9(0.8)$ & -3.463 & 0.001 \\
\hline
\end{tabular}

*Sig. (2-tailed)

were found across all dimensions in both settings, with Cypriot students (mean 4.0-4.7 including both settings) reporting a higher level of perceived knowledge. Both, Cypriot and Greek students reported the highest knowledge on the dimension "clinical safety" in both settings and the least knowledge on the dimension "Working in teams with other health professionals" again in both settings. Remarkably, the difference in the mean scores between the two countries in the clinical setting ranged from 0,6 to 1 , with the dimension of clinical safety having the highest mean difference (Table 2).

\section{Differences in students' perceptions on "broader aspects of patient safety"}

Table 3 shows that the level of agreement of the Cypriot student perceptions of how broader patient safety issues were addressed within their educational program was significantly different $(p<0.05)$ from that of the Greek students. Comparing students' country of origin and years of study, the highest mean was expressed in the item "I gained a solid understanding that reporting adverse events and close calls can lead to change and can reduce reoccurrence of events". As for the Cypriot students, the least rated learning experience was on the item 'System' aspects of patient safety are well covered in our program" whereas, for the Greek students, it was the item "My scope of practice was very clear to me".
The item "There is consistency in how patient safety issues are dealt with by preceptors in the clinical setting" followed as the second least-rated learning experience for both Cypriot and Greek students. The t-test revealed a statistically significant difference between the two countries of study in all items. Concerning the years of study, in most of the items, there was no significant difference between three and four-year students $(p>0.05)$ except of two items "I had sufficient opportunity to learn" and "System aspects of patient safety are well covered in our program" (Table 3).

\section{Discussion}

In this study, overall, students reported that they were more confident in their knowledge about patient safety gained in the classroom setting than in the clinical setting. These findings are similar to some studies $[37,38$, $44,46,61,65,66]$, although other studies reported mixed results, with reported clinical scores being higher than the class scores in more than half of the dimensions $[9,45,65]$. Classroom is perceived as a safe environment of learning about working in multi-professional teams, understanding the system-based nature of patient safety problems [50] and being more confident to speak up $[66,67]$. As $50 \%$ of the student programme is completed in clinical practice, its contribution to professional socialisation is identified. However, students feel unprepared when entering a clinical practice environment. If 


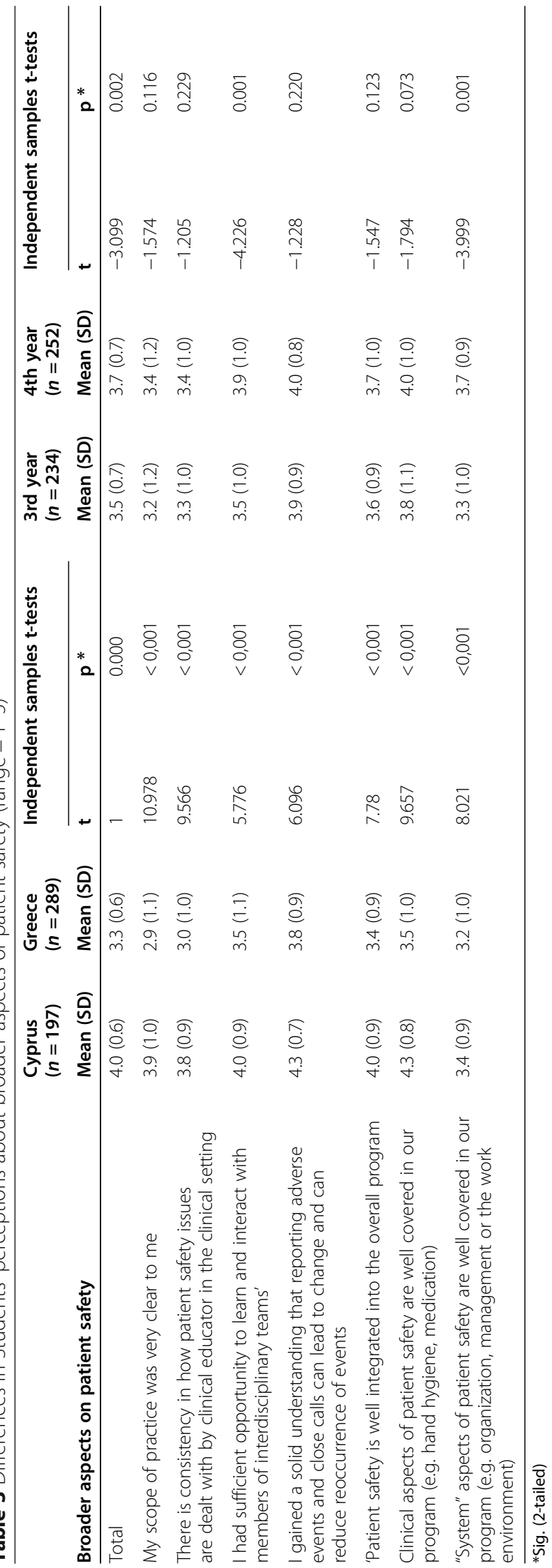


education in academic settings is too theoretical, nursing students may consider themselves as unsafe for patient care $[12,39]$. In clinical practice, the nurse educator's (a member of university staff) and the mentor's (an experience clinical nurse) incompetence as well as a defensive, concealing and blaming work environment were among the essential challenges to involve student into practice safety $[49,68]$. The insufficient support from nurse educator was reflected in the encouragement to do things beyond their scope of practice or inconsistent with the student's ethics and theory [69]. Further barriers appear after nursing students have realised that their mentors do not allocate enough time to teach patient safety or to assess them faithfully and adequately[49]. The dominant attitude of "getting the work done" and "following the rules" in the ward discourage students from questioning the procedures as they wish to conform rather than challenge the practices [40,70]. Students just do routine work without compliance with the standards of caring principles and patient-centered approach [68]. This approach is not appropriate in the structure of systemwide patient safety knowledge.

The above consideration has been supported by the findings of this study and earlier studies. Students valued learning about patient safety on the technical aspects higher than the sociocultural aspects in both settings. The findings are consensus to other studies [44-46]. That indicates that a system-based approach is not realised by the students during their education $[42,51]$, as they are not engaged in learning the organisational strategies and systems in the clinical setting [39, 42]. This is an alarming finding as national and international reports address patient safety on a system-wide basis [13, 30, 71]. Nursing students enter the profession with an idealised view of nursing, which declines with increasing clinical exposure, as reality does not meet their expectations and their ideas related to professionalism (caring and compassion) $[70,72,73]$, respectıvely and the conf1dence in learning about sociocultural aspects [37, 44].

The least agreement in this study in both settings was found in teamwork among all dimensions across countries and among years of study, while effective communication was valued higher in both settings. This weakness in interprofessional teamworkıng knowledge is supported with previous studies in Canada [38, 67], Finland $[50,51]$, Korea [61], Saudi Arabia [74], USA [23, 75] and Australia [44]. The findings support Cresswell et al., (2013) conclusion that students have been taught about safety in isolation from healthcare students of different disciplines. However, the suggestion "Interprofessional team training of nurses, physicians, and other health care providers should begin when they are students and proceed throughout their careers"[76]. Team culture was considered a strong influence in students' decision on whether to speak up or remain silent and is reflected in the relationship with their mentor and other team members $[39,68]$ and was valued as a strong ethical responsibility to prevent errors [48]. Effective interprofessional collaboration has been found to prevent adverse patient safety events [68] as it challenges any gaps or misconceptions about the role of each discipline and responsibility in problem solving [77-79].

This comparative study also revealed that Cypriot students were more positive about what they have learned about patient safety issues than Greek students for all dimensions and in both settings. Similarly, former comparative studies $[50,51]$ indicated differences between British and Finnish students, with British students obtaining higher knowledge in both settings and appreciating knowledge, skills, and attitudes on patient safety issues more than Finnish students did. These perceived differences reflected less training of skills in patient safety incidents received by the Finnish students. This is either due to the fact that England-UK patient safety work was ahead of Finland (i.e.introducing guidelines for patient safety since 2004) or because Finnish students' experience focused on the traditional approach of blaming the individual [58]. Adding to these explanations, in the current study the perceived differences might be attributed to historical and political factors; for example, nursing education in Cyprus has been influenced to a great extent by the British colonial [59]. Other possible reasons are the different style of clinical supervision model used (i.e. mentor), the status of nurse educator ( i.e. employed or not by the university) and the status of students in clinical practice (i.e. supernumerary)[80, 81].

On the other hand, Greece has been in a profound economic crisis since 2010, which has affected the health care system and education [82]. Today, Greece faces significant nursing staff shortage as the ration of nurses per 1000 inhabitants is the lowest in the EU [83]. Nursing understaffing in associated with the fact that Greece faces the unusual situation of having more medical doctors than nurses, in a ration of one nurse per doctor [84, 85 ] and almost half of the faculty members are medical doctors. This reality has consequently led to a medicallydominated care system in which the majority of care decisions are made by doctors, limitating nurses' scope of practice. Besides, the negative clinical, educational learning opportunities may be partly related to the presence of assistant nurses to perform nursing duties which are incongruity to the respective training they have attained [85]. As a consequence, the environment is anything but ideal for learning about safe practice having in mind that students' professional socialisation in clinical learning is deeply influenced by observing assistant nurses [39]. Under this sight, it is admitted that poor caring is caused by the work system that does not allow nurses to perform 
to the best of their abilities [70]. In a broader view, the perceived differences may be associated to cultural diversity [51], the lack of consensus or clarity as to specific patient safety learning outcomes at European directives, curriculum and guidelines,[14] and the universities' autonomy to accept new branches of nursing education [83].

As far as the years of study are concerned, progress in nursing students' knowledge about patient safety tended to remain stable or increased across the years in both settings in all dimensions. This finding is consistent with Alquwez et al. [74] study. According to Benner [86], knowledge is embedded in expertise which develops through experience and exposure to clinical situations. However, inconsistency in this finding was found with the score declining across the years [37, 44, 65, 66]. This can either suggest that first-year students have less insight into their skills and abilities or that the more experienced ones have a better understanding of what patient safety is about and what is needed to ensure they practice in a 'safe' manner [44].

As for students' perceptions of how broader patient safety issues were addressed, the students agreed upon the fact that their scope of practice is not clear. Early learning of the various healthcare professionals' tasks and the scope of the role of nursing students is essential for them in accepting responsibility for their actions, be able to reflect on and internalise their clinical experiences, and learn to collaborate as a team member [87]. Faculty should clearly state to students what is expected from the clinical experience [70] and ascertain that nurse educators ensure assessment and learning curriculum outcomes achievement [88].

\section{Limitations}

Data were collected by using a self-reported questionnaire where students may have overestimated or underestimated their awareness of patient safety knowledge. Also, data in Greece were collected from only one university in contradiction with Cyprus, which all universities were included. So, the transferability of the results needs to be carefully considered. Also, comparisons included students of different academic years without studying the progress of a single group of students over the years. Therefore, a longitudinal study covering the first to fourth-year period is recommended. Finally, students' perception of knowledge to the clinical environment provides only a general view as questions did not refer to a specific clinical setting.

\section{Conclusions}

The critical examination of the significant difference between class and clinical education indicate that the students perceived a gap between class and clinical practice. The view that patient safety competency cannot be acquired easily in a classroom alone provides an account to nurse educators' endeavours to promote a dynamic interaction of knowledge among classroom and clinical practice and alert students to the realities of healthcare systems.

This study showed teamwork as the less covered competency in nursing education. A clear description of the scope of the role of nursing students and understanding the different healthcare professionals' roles and responsibilities are essential for effective teamwork, collaboration and enhancement of safer care by promoting understanding of different roles and responsibilities. These results indicate the lack of specific patient safety competencies in nursing students. These differences in students' perceived competencies of patient safety, among two European Greek-speaking countries, clearly show that there is still inconsistency among patient safety education approaches and assessment methods despite the attempts to standardise nurse regulation and registration practices across Europe.

The impact of national patient safety efforts and guidance to nursing curricula and the influence of years of study on the patient safety competence of nursing students on the specific clinical environment needs to be further studied. This information can be used to update and design an international framework about the patient safety nursing curriculum adapted to national and cultural specificities as well as the students' learning objectives. The "...development it would seem that more than a series of statements relating to patient safety is required"(p.138)[14].

Abbreviations

H-PEPSS: Health Professional Education Patient Safety Survey

\section{Acknowledgements \\ The authors would like to thank undergraduate nursing students for their participation in the study and Maria Botonaki for the language editing.}

Authors' contributions

All Authors read and approved the manuscript. (1) Study design: MD, EP $A C, A M, C L$. (2) data collection and analysis: MD, EP, AM. (3) manuscript preparation: MD, EP, AC, AM,CL.

\section{Funding}

No funding support for the research.

\section{Availability of data and materials}

Data, to some extent, are presented within the manuscript. Authors do not wish to share their data because these data analysis are part of a PhD thesis which is still in progress. However, additional data can be available from the corresponding author on reasonable request after the completion of the thesis. All dataset will be submitted to the library of the Cyprus Unıversity of Technology along with my thesis.

\section{Declarations}

Ethics approval and consent to participate

For conducting the study, approval was given (a) from Cyprus National Bioethics Committee (CNBC EP 2018.01.61), (b) from the University Board of each university for delivering questionnaires to nursing students. As far as 
the partıcıpants' consent is concerned, after the approval of bıothıcs committee, completing and returning the questionnaire was considered as consent to participate in the study. Also, permission to use the research instrument was obtained by Dr Liane R Ginsburg, (via email 11/1/2018, Igins@yorku.ca ).

\section{Consent for publication}

Not applicable.

\section{Competing interest}

The authors have declared no conflict of interest.

\section{Author details}

${ }^{1}$ Department of Nursing, School of Health Sciences, Cyprus University of Technology, 15 Vragadinou Str, 3041 Limassol, Cyprus. ²Department of Nursing, National and Kapodistrian University, 123 Papadiamadopoulou str, 11517 Goudi, Athens, Greece.

Received: 27 September 2020 Accepted: 25 May 2021

Published online: 25 June 2021

\section{References}

1. International Council Of Nurse. THE ICN CODE OF ETHICS FOR NURSES International Council of Nurses [Internet]. International Council of Nurses. Geneva, Switzerland; 2012

2. Francis R. Freedom to Speak Up. An independent review into creating an open and honest reporting culture in the NHS [Internet]. Great Britain; 2015. Available from: https://doi.org/10.7748/ns.31.27.32.s39.

3. World Health Organization. Patent Safety Fact File [Internet]. WHO. 2019 [cited 2020 Jun 15].

4. Special Eurobarometer 411. Patient safety and quality of care [Internet]. European commision. Brussel; 2014

5. Slawomirski L, Auraaen A, Klazinga NS. The economics of patient safety [Internet]. OECD Health Working Papers. 2017.

6. World Health Organsisation (WHO). Patient safety [Internet]. WHO. World Health Organization; 2020. [cited 2020 Jun 15].

7. Albrecht RM. Patient safety: The what, how, and when. Am J Surg. 2015; 210(6):978-82. Available from: https://doi.org/10.1016/j.amjsurg.2015.09.003.

8. Reason J. Human error: Models and management. Br Med J. 2000;320(7237): 768-70. Available from: https://doi.org/10.1136/bmj.320.7237.768.

9. Ginsburg L, Castel E, Tregunno D, Norton PG. The H-PEPSS: An instrument to measure health professionals' perceptions of patient safety competence at entry into practice. BMJ Qual Saf. 2012 Aug;21(8):676-84. Available from: https://doi.org/10.1136/bmjqs-2011-000601.

10. Frank J, Brien S. The Safety Competencies: Enhancing Patient Safety Acros the Health Professions [Internet]. Canadian Patient Safety Institute. 2009 [cited 2020 Jul 27]. Available from: https://doi.org/10.1136/bmjqs-2011000148.

11. Gordon M, Baker P, Catchpole K, Darbyshire D, Schocken D. Devising a consensus definition and framework for non-technical skills in healthcare to support educational design: A modified Delphi study. Med Teach. 2015; 37(6):572-7. Available from: https://doi.org/10.3109/0142159X.2014.959910.

12. Vaismoradi M, Salsali M, Marck P. Patient safety: Nursing students' perspectives and the role of nursing education to provide safe care. Int Nurs Rev. 2011;58(4):434-42. Available from: https://doi.org/10.1111/j.14667657.2011.00882x

13. World Health Organization (WHO). Patient safety curriculum guide. MultiProfessional Edition. [Internet]. World Health Organisation. 2011. Available from: https://doi.org/10.1097/00001888-200005000-00082.

14. Kirwan M, Riklikiene O, Gotlib J, Fuster P, Borta M. Regulation and current status of patient safety content in pre-registration nurse education in 27 countries: Findings from the Rationing - Missed nursing care (RANCARE) COST Action project. Nurse Educ Pract. 2019;37(April):132-40. Available from: https://doi.org/10.1016/j.nepr.2019.04.013.

15. Duckett S, Moran G. Why you should avoid hospitals in January. 2018. Retrieved from. http://theconversation.com/why-you-should-avoid-hospitalsin-january-89857 [cited 2020 Jul 16]

16. Murray M, Sundin D, Cope V. New graduate registered nurses' knowledge of patient safety and practice: A literature review. J Clin Nurs. 2018;27(1-2):3147. Available from: https://doi.org/10.1111/jocn.13785.
17. Aiken LH, Clarke SP, Cheung RB, Sloane DM, Silber JH. Educational Levels of Hospital Nurses and Surgical Patient Mortality. J Am Med Assoc. 2003; 290(12):1617-23. Available from: https://doi.org/10.1001/jama.290.12.1617.

18. Aiken LH, Sloane DM, Bruyneel L, Van Den Heede K, Griffiths P, Busse R, et al. Nurse staffing and education and hospital mortality in nine European countries: A retrospective observational study. Lancet. 2014;383(9931):182430. Available from: https://doi.org/10.1016/S0140-6736(13)62631-8.

19. Schubert M, Ausserhofer D, Desmedt M, Schwendimann R, Lesaffre E, Li B, et al. Levels and correlates of implicit rationing of nursing care in Swiss acute care hospitals-A cross sectional study. Int J Nurs Stud. 2013;50(2):2309. Available from: https://doi.org/10.1016/j.jijnurstu.2012.09.016.

20. Kirwan M, Matthews A, Scott PA. The impact of the work environment of nurses on patient safety outcomes: A multi-level modelling approach. Int J Nurs Stud. 2013;50(2):253-63. Available from: https://doi.org/10.1016/j. ijnurstu.2012.08.020.

21. Bruyneel L, Li B, Ausserhofer D, Lesaffre E, Dumitrescu I, Smith HL, et al. Organization of Hospital Nursing, Provision of Nursing Care, and Patient Experiences with Care in Europe. Med Care Res Rev. 2015;72(6):643-64. Available from: https://doi.org/10.1177/1077558715589188.

22. Steven A, Tella S, Turunen H, Flores Vizcaya-Moreno M, Pérez-Cañaveras RM, Porras J, et al. Shared learning from national to international contexts: a research and innovation collaboration to enhance education for patient safety. J Res Nurs. 2019;24(3-4):149-64. Available from: https://doi.org/10.11 77/1744987118824628

23. Rebeschi LM. Perceived Patient Safety Competence of Baccalaureate Nursing Students: A Descriptive Comparative Study. SAGE Open Nurs. 2020; 6:1-9. Available from: https://doi.org/10.1177/2377960820930134.

24. Kohn LT, Corrigan JM, Donaldson MS. To Err Is Human. Building a Safer Health System. 1999. 1-34 p.

25. Department of Health. An organisation with a memory [Internet]. Vol. 28, British Journal of Nursing. London; 2000 [cited 2020 Jul 16]. Available from: https://doi.org/10.12968/bjon.2019.28.2.81.

26. European Network for Patient Safety (EUNetPaS). A General Guide for Education and Training in Patient Safety [Internet]. European commision. 2010.

27. World Health Organization (WHO). Transforming and Scaling up health professionals' education and training [Internet]. WHO publication. 2013 [cited 2020 Jul 18]. Available from: https://doi.org/10.1017/CBO978110741 $5324 \$ 4004$.

28. World Health Organization. World alliance for patient safety: WHO patient safety curriculum guide for medical schools [Internet]. WHO. 2009.

29. Cronenwett L, Sherwood G, Gelmon SB. Improving quality and safety education: The QSEN Learning Collaborative. Nurs Outlook. 2009;57(6):30412. Available from: https://doi.org/10.1016/j.outlook.2009.09.004.

30. Cronenwett L, Sherwood G, Barnsteiner J, Disch J, Johnson J, Mitchell P et al. Quality and safety education for nurses. Nurs Outlook. 2007:55(3):12231. Available from: https://doi.org/10.1016/j.outlook.2007.02.006.

31. Walton MM, Shaw T, Barnet S, Ross J. Developing a national patient safety education framework for Australia. Qual Saf Heal Care. 2006;15(6):437-42. Available from: https://doi.org/10.1136/qshc.2006.019216.

32. Mansour M, Skull A, Parker M. Evaluation of World Health Organization Multi-Professional Patient Safety Curriculum Topics in Nursing Education: Pre-test, post-test, none-experimental study. J Prof Nurs. 2015;31(5):432-9. Available from: https://doi.org/10.1016/j.profnurs.2015.03.002.

33. Mansour M. Examining patient safety education in pre-registration nursing curriculum: Qualitative study. J Nurs Educ Pract. 2013;3(12):157-67. Available from: https://doi.org/10.5430/jnep.v3n12p157.

34. Patient Safety and Quality of Care Working Group (PSQCWG). Key findings and recommendations on Education and training in patient safety across Europe Work of the Education and Training in Patient Safety Subgroup of the Patient Safety and Quality. of Care Working Group of the European Commission [Internet]; 2014.

35. Duhn L, Karp S, Oni O, Edge D, Ginsburg L, Van Den Kerkhof E. Perspectives on patient safety among undergraduate nursing students. J Nurs Educ. 2012;51(9): 526-31. Available from: https://doi.org/10.3928/01484834-20120706-04.

36. Gjessing K, Torgé CJ, Hammar M, Dahlberg J, Faresjö T. Improvement of quality and safety in health care as a new interprofessional learning module - Evaluation from students. J Multidiscip Healthc. 2014;7:341-7. Available from: https://doi.org/10.2147/JMDH.S62619.

37. Lukewich J, Edge DS, Tranmer J, Raymond J, Miron J, Ginsburg L, et al. Undergraduate baccalaureate nursing students' self-reported confidence in 
learning about patient safety in the classroom and clinical settings: An annual cross-sectional study (2010-2013). Int J Nurs Stud. 2015;52(5):930-8. Available from: https://doi.org/10.1016/j.jinurstu.2015.01.010.

38. Raymond JM, Medves JM, Godfrey CM. Baccalaureate nursing students' confidence on patient safety. J Nurs Educ Pract. 2017;7(6):56. Available from: https://doi.org/10.5430/jnep.v7n6p56.

39. Steven A, Magnusson C, Smith P, Pearson PH. Patient safety in nursing education: Contexts, tensions and feeling safe to learn. Nurse Educ Today. 2014;34(2):277-84. Available from: https://doi.org/10.1016/j.nedt.2013.04.025.

40. Tregunno D, Ginsburg L, Clarke B, Norton P. Integrating patient safety into health professionals' curricula: A qualitative study of medical, nursing and pharmacy faculty perspectives. BMJ Qual Saf. 2014;23(3):257-64. Available from: https://doi.org/10.1136/bmjgs-2013-001900.

41. Usher K, Woods C, Conway J, Lea J, Parker V, Barrett F, et al. Patient safety content and delivery in pre-registration nursing curricula: A national crosssectional survey study. Nurse Educ Today. 2018;66:82-9. Available from: https://doi.org/10.1016/j.nedt.2018.04.013.

42. Cresswell K, Howe A, Steven A, Smith P, Ashcroft D, Fairhurst K, et al. Patient safety in healthcare preregistration educational curricula: Multiple case study-based investigations of eight medicine, nursing, pharmacy and physiotherapy university courses. BMJ Qual Saf. 2013;22(10):843-54. Available from: https://doi.org/10.1136/bmjgs-2013-001905.

43. Vaismoradi M, Bondas $\mathrm{T}$, Jasper $\mathrm{M}$, Turunen $\mathrm{H}$. Nursing students' perspectives and suggestions on patient safety-implications for developing the nursing education curriculum in iran. Nurse Educ Today [Internet]. 2014; 34(2):265-70. Available from: https://doi.org/10.1016/..nedt.2012.10.002.

44. Usher K, Woods C, Parmenter G, Hutchinson M, Mannix J, Power T, et al. Self-reported confidence in patient safety knowledge among Australian undergraduate nursing students: A multi-site cross-sectional survey. Int J Nurs Stud. 2017;71:89-96. Available from: https://doi.org/10.1016/j.jinurstu.2017.03.006.

45. VanDenKerkhof E, Sears N, Edge DS, Tregunno D, Ginsburg L. Patient safety in practical nurses' education: A cross-sectional survey of newly registered practical nurses in Canada. Nurse Educ Today. 2017;51:48-56. Available from: https://doi.org/10.1016/j.nedt.2017.01.003.

46. Huang FF, Shen XY, Chen XL, He LP, Huang SF, Li JX. Self-reported confidence in patient safety competencies among Chinese nursing students: A multi-site cross-sectional survey. BMC Med Educ. 2020;20(1):110. Available from: https://doi.org/10.1186/s12909-020-1945-8.

47. Levett-Jones T, Andersen P, Bogossian F, Cooper S, Guinea S, Hopmans R, et al. A cross-sectional survey of nursing students' patient safety knowledge. Nurse Educ Today. 2020;88(August 2019):104372. Available from: https://doi. org/10.1016/j.nedt.2020.104372.

48. Hensel D. Typologies of professional identity among graduating baccalaureate-prepared nurses. J Nurs Scholarsh. 2014;46(2):125-33. Available from: https://doi.org/10.1111/jnu.12052.

49. Attree $\mathrm{M}, \mathrm{Cooke} \mathrm{H}$, Wakefield A. Patient safety in an english pre-registration nursing curriculum. Nurse Educ Pract. 2008;8(4):239-48. Available from: https://doi.org/10.1016/j.nepr.2007.09.003.

50. Tella S, Smith NJ, Partanen P, Turunen H. Learning Patient Safety in Academic Settings: A Comparative Study of Finnish and British Nursing Students' Perceptions. Worldviews Evidence-Based Nurs. 2015;12(3):154-64. Available from: https://doi.org/10.1111/wvn.12088.

51. Tella S, Smith NJ, Partanen P, Jamookeeah D, Lamidi ML, Turunen H. Learning to ensure patient safety in clinical settings: Comparing Finnish and British nursing students' perceptions. J Clin Nurs. 2015;24(19-20):2954-64. Available from: https://doi.org/10.1111/jocn.12914.

52. Bressan V, Stevanin S, Bulfone G, Zanini A, Dante A, Palese A. Measuring patient safety knowledge and competences as perceived by nursing students: An Italian validation study. Nurse Educ Pract. 2016;16(1):209-16 Available from: https://doi.org/10.1016/j.nepr.2015.08.006

53. Stevanin S, Bressan V, Bulfone G, Zanini A, Dante A, Palese A. Knowledge and competence with patient safety as perceived by nursing students: The findings of a cross-sectional study. Nurse Educ Today. 2015;35(8):926-34. Available from: https://doi.org/10.1016/..nedt.2015.04.002

54. Killam $L A$, Mossey S, Montgomery P, Timmermans KE. First year nursing students' viewpoints about compromised clinical safety. Nurse Educ Today. 2013;33(5):475-80. Available from: https://doi.org/10.1016/j.nedt.2012.05.010.

55. Bianchi M, Bressan V, Cadorin L, Pagnucci N, Tolotti A, Valcarenghi D, et al. Patient safety competencies in undergraduate nursing students: a rapid evidence assessment. J Adv Nurs. 2016;72(12):2966-79. Available from: https://doi.org/10.1111/jan.13033.
56. Lee NJ, Jang H, Park SY. Patient safety education and baccalaureate nursing students' patient safety competency: A cross-sectional study. Nurs Heal Sci. 2016;18(2):163-71. Available from: https://doi.org/10.1111/nhs.12237.

57. Tella S, Liukka M, Jamookeeah D, Smith NJ, Partanen P, Turunen H. What do nursing students learn about patient safety? an integrative literature review. J Nurs Educ. 2014;53(1):7-21. Available from: https://doi.org/10.3928/01484 834-20131209-04

58. European Parliament. Directive 2013/55/EU of the European Parliament and of the council of 20 November 2013 amending Directive 2005/36/EC on the recognition of professional qualifications and Regulation (EU) No 1024/2012 on administrative cooperation through the Internal Mark [Internet]. Official Journal of the European Union. 2013. [cited 2020 Jul 18].

59. Dimitriadou M, Papastavrou E, Efstathiou G, Theodorou M. Baccalaureate nursing students' perceptions of learning and supervision in the clinical environment. Nurs Heal Sci. 2015;17(2):236-42. Available from: https://doi. org/10.1111/nhs. 12174 .

60. Brynildsen G, Bjørk IT, Berntsen K, Hestetun M. Improving the quality of nursing students' clinical placements in nursing homes: An evaluation study. Nurse Educ Pract. 2014;14(6):722-8. Available from: https://doi.org/1 0.1016/j.nepr.2014.09.004.

61. Hwang Jl, Yoon TY, Jin HJ, Park Y, Park JY, Lee BJ. Patient safety competence for final-year health professional students: Perceptions of effectiveness of an interprofessional education course. J Interprof Care. 2016;30(6). Available from: https://doi.org/10.1080/13561820.2016.1218446.

62. Chen L, Huang F, Yuan X, Song J, Chen L. An assessment of the reliability and factorial validity of the chinese version of the health professional education in patient safety survey (H-PEPSS). Front Psychol. 2019;10(SEP):110. Available from: https://doi.org/10.3389/fpsyg.2019.02183.

63. WHO. WHO | Process of translation and adaptation of instruments [Internet] [cited 2021 Mar 14].

64. European Commission. What does the General Data Protection Regulation (GDPR) govern? | European Commission [Internet]. European Commission. 2018 [cited 2020 Sep 14].

65. Colet PC, Cruz JP. Patient Safety Competence of Nursing Students in Saudi Arabia: A Self-Reported Survey. Int J Health Sci (Qassim). 2015;9(4):411-9. Available from: https://doi.org/10.12816/0031231.

66. Mbuthia NN, Moleki MM. Preregistration nursing students' perceived confidence in learning about patient safety in selected Kenyan universities. Curationis. 2019;42(1):1-7. Available from: https://doi.org/10.4102/curationis. v42i1.1974.

67. Ginsburg LR, Tregunno D, Norton PG. Self-reported patient safety competence among new graduates in medicine, nursing and pharmacy. BMJ Qual Saf. 2013;22(2):147-54. Available from: https://doi.org/10.1136/bmjgs-2012-001308.

68. Fisher M, Kieman M. Student nurses' lived experience of patient safety and raising concerns. Nurse Educ Today. 2019;77:1-5. Available from: https://doi. org/10.1016/j.nedt.2019.02.015.

69. Montgomery P, Killam L, Mossey S, Heerschap C. Third year nursing students' viewpoints about circumstances which threaten safety in the clinical setting. Nurse Educ Today. 2014;34(2):271-6. Available from: https:// doi.org/10.1016/j.nedt.2013.09.019.

70. Raso A, Ligozzi L, Garrino L, Dimonte V. Nursing profession and nurses' contribution to nursing education as seen through students' eyes: A qualitative study. Nurs Forum. 2019;54(3):414-24. Available from: https://doi. org/10.1111/nuf.12349

71. National Patient Safety Agency (NPSA). Seven steps to patient safety An overview guide for NHS staff [Internet]. 2nd print. 2004.

72. Felstead IS, Springett K. An exploration of role model influence on adult nursing students' professional development: A phenomenological research study. Nurse Educ Today. 2016;37:66-70. Available from: https://doi.org/10.1 016/j.nedt.2015.11.014

73. Traynor M, Buus N. Professional identity in nursing: UK students' explanations for poor standards of care. Soc Sci Med. 2016;166:186-94. Available from: https://doi.org/10.1016/j.socscimed.2016.08.024.

74. Alquwez N, Cruz JP, Alshammari F, Felemban EM, Almazan JU, Tumala RB, et al. A multi-university assessment of patient safety competence during clinical training among baccalaureate nursing students: A cross-sectional study. J Clin Nurs [Internet]. 2019 May 1 [cited 2020 Jul 29];28(9-10):177181. Available from: https://doi.org/10.1111/jocn.14790.

75. Shanty JA, Gropelli T. Self-reported patient safety competence among nursing, respiratory care, and nuclear medicine technology students. J Allied Health. 2018;47(2):141-6. 
76. Institute of Medicine(IOM). The future of nursing: Leading change, advancing health [Internet]. The Future of Nursing: Leading Change, Advancing Health. Washington, D.C: The National Academies Press; 2011. 1 671 p. Available from: https://doi.org/10.17226/12956.

77. Abbott AA, Fuji KT, Galt KA, Paschal KA. How Baccalaureate Nursing Students Value an Interprofessional Patient Safety Course for Professional Development. ISRN Nurs. 2012;1-7. Available from: https:/doi.org/10.5402/2012/401358.

78. Samuriwo R, Laws E, Webb K, Bullock A. "I didn't realise they had such a key role." Impact of medical education curriculum change on medical student interactions with nurses: a qualitative exploratory study of student perceptions. Adv Heal Sci Educ. 2019;25(1):75-93. Available from: https://doi. org/10.1007/s10459-019-09906-4.

79. Leotsakos A, Ardolino A, Cheung R, Zheng H, Barraclough B, Walton M. Educating future leaders in patient safety. J Multidiscip Healthc. 2014;7:3818. Available from: https://doi.org/10.2147/JMDH.S53792.

80. Immonen K, Oikarainen A, Tomietto M, Kääriäinen M, Tuomikoski AM, Kaučič $\mathrm{BM}$, et al. Assessment of nursing students' competence in clinical practice: A systematic review of reviews. Int J Nurs Stud. 2019;100. Available from: https://doi.org/10.1016/j.jjnurstu.2019.103414.

81. Papastavrou E, Dimitriadou M, Tsangari H, Andreou C. Nursing students' satisfaction of the clinical learning environment: A research study. BMC Nurs [Internet]. 2016 Jul 19 [cited 2021 Jan 17];15(1):44. Available from: https:// doi.org/10.1186/s12912-016-0164-4.

82. Economou C, Kaitelidou D, Karanikolos M, Maresso A. Health Systems in Transition Greec: health system review [Internet]. European Observatory on Health Systems Policies. 2017;Vol. 19:204 p.

83. Palese A, Zabalegui A, Sigurdardottir AK, Bergin M, Dobrowolska B, Gasser C, et al. Bologna process, more or less: Nursing education in the European Economic Area: A discussion paper. Int J Nurs Educ Scholarsh. 2014;11(1):111. Available from: https://doi.org/10.1515/ijnes-2013-0022.

84. Organization for Economic Co-operation and Development (OECD). "Life expectancy by sex and education level", in Health at a Glance 2017 [Internet]. OECD iLibrary. 2019 [cited 2020 Jul 17]. Available from: https://doi. org/10.1787/4dd50c09-en.

85. Rafferty AM, Busse R, Zander-Jentsch B, Sermeus W, Luk Bruyneel. Health systems through nursing: Evidence from 14 European countries [Internet]. World Health Organisation; 2019.

86. Munjas BA. From Novice To Expert: Excellence And Power In Clinical Nursing Practice [Internet]. Vol. 23, Journal of Psychosocial Nursing and Mental Health Services. Menlo Park: Deakin University; 1985. 39-39 p. Available from: https://doi.org/10.3928/0279-3695-19850501-10.

87. Oermann MH, Shellenbarger T. Clinical Education in Nursing: Current Practices and Trends [Internet]. Clinical Education for the Health Professions. Theory and Practice. 2020. 1-20 p. Available from: https://doi.org/10.1007/ 978-981-13-6106-7\$410-1.

88. World Health Organization. Nurse Educator Core Competencies [Internet] WHO. 2016. Available from: http://www.who.int/about/licensing/copyright_ form/index.html.

89. World Health Organization (WHO). Global strategic directions for strengthening nursing and midwifery 2016-2020 [Internet]. Vol. 1. WHO publication. 2016 [cited 2020 Jul 18]. Available from: https://doi.org/10.1007/ s00737-011-0247-x.

\section{Publisher's Note}

Springer Nature remains neutral with regard to jurisdictional claims in published maps and institutional affiliations.

Ready to submit your research? Choose BMC and benefit from:
- fast, convenient online submission
- thorough peer review by experienced researchers in your field
- rapid publication on acceptance
- support for research data, including large and complex data types
- gold Open Access which fosters wider collaboration and increased citations
- maximum visibility for your research: over 100M website views per year
At BMC, research is always in progress.
Learn more biomedcentral.com/submissions

